\title{
Comparison of Harakeke with Hemp Fibre as a Potential Reinforcement in Composites
}

\author{
M.G Aruan Efendy ${ }^{\mathrm{a}, \mathrm{b}}$ and K. L. Pickering ${ }^{\mathrm{a}}$ \\ ${ }^{\text {a }}$ Faculty of Science and Engineering, University of Waikato, New Zealand \\ ${ }^{\mathrm{b}}$ Faculty of Civil Engineering, Universiti Teknologi MARA, Malaysia
}

\section{Corresponding author:}

M.G Aruan Efendy,

Tel.: +64 22194491

E mail addresses: $\underline{\text { mghazali_ae@yahoo.com, aebm1@waikato.ac.nz }}$

\section{ABSTRACT}

The objective of this study was to characterize the performance of untreated and chemically treated harakeke fibre (a leaf fibre from a plant native to New Zealand) and compare with hemp fibre to assess its use as potential reinforcement in composites. Alkali treatment is among the most popular treatments used to remove unwanted fibre constituents such as pectin, hemicellulose and waxes; it can enhance fibre properties, fibre separation, interfacial bonding and fibre dispersion within a composite. Physical and mechanical properties of untreated and alkali treated fibres were assessed using single fibre tensile testing, X-ray diffraction (XRD), scanning electron microscopy (SEM) and thermal analysis using thermogravimetric analysis (TGA). Untreated harakeke fibre was found to be lower in tensile strength compared to untreated hemp fibre. It was also found that the tensile strength of harakeke and hemp fibres treated with $5 \mathrm{wt} \% \mathrm{NaOH} / 2 \mathrm{wt} \% \mathrm{Na}_{2} \mathrm{SO}_{3}$ and $5 \mathrm{wt} \% \mathrm{NaOH}$ was not significantly affected and these fibres had good fibre separation. However, alkali treatment was found to lead to higher crystallinity index $\left(I_{c}\right)$ and better thermal stability for harakeke as well as hemp fibres. 


\section{KEYWORDS:}

A. Discontinuous reinforcement; B. Mechanical properties; D. Mechanical testing;

E. Surface treatment

\section{INTRODUCTION}

Increased environmental awareness has led to growing interest in the use of more sustainable materials. Typical construction materials have large ecological footprints; production of synthetic composites is generally energy intensive and construction and demolition debris constitute a large percentage of landfill volume [1]. Natural-fibre-reinforced bio-derived polymer matrix composites, commonly referred to as bio-composites have gained renewed interest over the past few decades because of their low material costs, low densities, high specific moduli and environmentally friendly appeal, as well as their low production energy requirements [2]. The natural fibres used are renewable, nonabrasive, can be incinerated for energy recovery and they give less concern regarding health and safety during handling than synthetic fibres. Their excellent price-performance ratios at low weight in combination with their low environmental impact has resulted in increasing uptake by engineering markets such as the automotive and construction industries [3].

Many studies have been carried out internationally to assess the possibility of using natural fibre-composites for non-structural and structural applications [4-8]. However, development of such low cost materials with elevated durability and high mechanical performance is still a real challenge faced by engineers of the $21^{\text {st }}$ century to enable natural fibre to be put on a par with synthetic fibre. Important factors regarding composite performance are:

- the fibre, including fibre type, alignment and length,

- the matrix used and 
- the interfacial bonding which enables transfer of the applied load to the fibres

Weak interfacial bonding between the reinforcing agent and the matrix in natural reinforced composites is a major drawback which limits their application. Interfacial strength plays a vital role in determining the mechanical properties of composite materials. A strong interface provides composites that display good strength and stiffness but tend to be brittle. A weaker interface on the other hand, may reduce the stress transfer from matrix to the fibre, hence the composite may display lower strength and stiffness but may in contrast have increased toughness. Depending on the application, interfacial strength can be engineered by modifying the fibre surface using physical and chemical treatment and modifying the matrix by addition of coupling agent. The literature shows that these methods increase compatibility and potential reactivity between fibre and matrix and hence increase the interfacial strength between matrix and reinforcing agent [9].

The present work is a preliminary study of the mechanical and physical properties of harakeke fibre compared to hemp fibre including the effect of alkali treatment. Harakeke is a monocotyledonous plant endemic to New Zealand and is renowned for its fibre which was used by early European settlers in New Zealand as a replacement for European flax and here is commonly called 'native flax'. It fibre can be extracted from upper and lower side of its leaves. However, unlike European flax, from which fibre is extracted from stalk, the fibre from harakeke is extracted from the leaves of this plant. The leaves are stiff and tough and can grow up to $3 \mathrm{~m}$ long and $125 \mathrm{~mm}$ wide. The favourable strength and stiffness of the fibre and mechanisation of the extraction around the 1920s resulted in an expansion of the harakeke fibre industry with the fibres becoming an important export commodity used in a variety of applications such as clothing, mats, baskets, ropes, fishing lines and nets $[10,11]$. The chemical composition 
of harakeke fibre is tabulated in Table 1[12]. Two different types of alkali with various concentrations were used in isolation or in combination with the aim of maximising the fibre properties for enhancement of mechanical and physical properties of composites. There are several papers published reporting the improvement of fibre properties when treated with various alkali treatments $[10,13,14]$, but only limited papers discussing the mechanical behaviour of single fibres, with none for harakeke that have been found by the authors. This work was aimed at acquiring a better understanding of the potential of these fibres for reinforcement in composites. Together with mechanical and physical assessments, this paper also includes analysis of fibre strength using Weibull statistics.

\section{EXPERIMENTAL}

\section{Materials}

Harakeke fibre was obtained from the Templeton Flax mill, Riverton. It was mechanically prepared and supplied in bundle form. Hemp fibre was locally grown from October 2012 and harvested in February 2013 after 120 days and donated by the Hemp Farm NZ Ltd. Green hemp stalks were dried exposed to air for two weeks and then the bast fibre was hand separated from the stalks.

\section{Methods}

\section{Alkali Fibre Treatment}

Alkali treatment was carried out using a laboratory scale pulp digester (normally used for paper making) at different temperatures and for different durations. Three alkali formulations were used in this investigation: $5 \mathrm{wt} \%$ sodium hydroxide $(\mathrm{NaOH})$, $10 \mathrm{wt} \% \mathrm{NaOH}$ and $5 \mathrm{wt} \% \mathrm{NaOH}$ with $2 \mathrm{wt} \%$ sodium sulphite $\left(\mathrm{Na}_{2} \mathrm{SO}_{3}\right)$. The chemicals used (purchased from Scharlau Chemie S.A.) were analytical grade $\mathrm{Na}_{2} \mathrm{SO}_{3}$ pellets and $\mathrm{NaOH}$ powder, both with $98 \%$ purity level. The abbreviations used for the fibres and treatments are shown in Table 2. 
The three alkali solutions were used with a fibre (harakeke or hemp) to solution ratio of 1:8 by weight. Predetermined amounts of harakeke and hemp fibres were placed in stainless steel canisters with pre-mixed $\mathrm{NaOH}$ and $\mathrm{Na}_{2} \mathrm{SO}_{3}$ solutions. The canisters were then placed into a small lab-scale pulp digester with the treatment cycles, controlled by a 4-step controlled programme, chosen based on preliminary screening trials. Trials had previously been conducted raising the temperature from ambient to a maximum temperature over 90 minutes. It had been demonstrated that treatment conducted for longer than 30 minutes at a temperature for more than $160^{\circ} \mathrm{C}$ reduced the tensile strength of hemp fibre considerably. However, with treatment conducted at less than $160^{\circ} \mathrm{C}$ the fibre tensile strength was maintained, but the separation of the fibre was very poor. Therefore, treatment at $160^{\circ} \mathrm{C}$ for 30 minutes was chosen for hemp fibre. For harakeke, it was found that in order to get fibre separation, treatment was required to be conducted at $170^{\circ} \mathrm{C}$ for at least 40 minutes, however, harakeke fibre treated at higher than $170^{\circ} \mathrm{C}$ was slightly degraded even though the fibre separation was improved. This is supported by research conducted elsewhere, such that treatment at $170^{\circ} \mathrm{C}$ was found to give the optimum fibre separation for harakeke [15]. Therefore, treatment at $170^{\circ} \mathrm{C}$ for 40 minutes was chosen for harakeke fibre.

\section{Scanning Electron Microscopy}

SEM micrographs of untreated and treated fibres were taken using a Hitachi S4100 field emission scanning electron microscope (SEM). Prior to SEM observation, the samples were mounted on aluminium stubs using carbon tape and then coated with plasma sputtering to avoid the sample becoming charged under the electron beam. SEM observation was carried out at $5 \mathrm{kV}$.

\section{Single Fibre Tensile Testing}

The tensile strength and Young's modulus of untreated, $\mathrm{NaOH}$ and $\mathrm{NaOH} / \mathrm{Na}_{2} \mathrm{SO}_{3}$ treated harakeke and hemp fibres were tested according to the ASTM 
D3379-75: Standard Test Method for Tensile Strength and Young's Modulus for HighModulus Single Filament Materials. Single fibres were mounted on $2 \mathrm{~mm}$ thick cardboard mounting-cards with a $2 \mathrm{~mm}$ gauge length as schematically shown in Figure 1. PVA glue was applied to hold the fibres to the cardboard and define the gauge length. Harakeke and hemp fibres, similar to other cellulosic fibres generally have variable cross-sectional areas and diameters along their length. To account for this, the diameter of the fibres was measured at five different points along the fibres length by means of an Olympus BX60F5 optical microscope. Typical single harakeke and hemp fibres observed under optical microscope are shown in Figure 2 and 3 respectively. It can be seen that harakeke fibre is finer than hemp fibre, but otherwise looked similar.

The apparent cross-sectional area of each fibre was then calculated using the mean fibre diameter and assuming a circular cross-section. The measured and mounted fibres were then placed in the grips of an Instron-4204 universal testing machine and the supporting sides of the mounting cards were cut using a hot-wire cutter. The fibres were then tensile tested to failure at a rate of $0.5 \mathrm{~mm} / \mathrm{min}$ using a $10 \mathrm{~N}$-load cell. 30 replicate samples were tested for each batch and average tensile strength (TS) and Young's moduli (YM) were obtained using the results from all specimens. As an extensometer cannot be used on such thin specimens, elongation of single fibres was determined through the displacement of the testing machine cross head. The crosshead displacement, however, is actually a combination of the fibre elongation as well as the crosshead deformation, specimen grips, and the cardboard mounting card. For accurate measurement of fibre elongation and Young's modulus, system compliance is required and was determined experimentally using related procedures described in ASTM D3375-75 [16]. In this study, specimens of different gauge lengths of 5, 10 and $15 \mathrm{~mm}$ of hemp and harakeke were prepared using similar set up used in single fibre testing. From the corresponding load-displacement curves for each specimen, the inverse of the 
slope of the initial linear region of the force versus cross-head displacement curve representing the apparent compliance was determined. By plotting indicated compliance against gauge length and extrapolating this function to zero gauge length, leads to the testing device compliance which was then used to calculate Young's modulus.

The data obtained for the tensile properties were statistically analysed using the two-parameter Weibull equation, which expresses the cumulative density function of the strength of the fibres as [17]:

$P_{f(L)}=1-\exp \left[-L\left(\frac{\sigma}{\sigma_{0}}\right)^{w}\right]$

where $P_{f(L)}$ is the probability of failure of a fibre of length $L$ at a stress less than or equal to $\sigma, \sigma_{0}$ is the Weibull scale parameter or characteristic stress, and $w$ is the shape parameter or Weibull modulus which describes the variability of the failure strength. Weibull parameters were estimated through the linear regression method, using the following estimator [18]:

$P=\frac{i}{n+1}$

where $n$ is the number of data points and $i$ the rank of the $i$-th data point.

Rearrangement of the two-parameter Weibull cumulative distribution expression (Equation 1) gives the following [19]:

$\ln \ln \left(\frac{1}{1-P_{f}}\right)=w \ln \sigma-w \ln \sigma_{0}+\ln L$

The scale and shape parameters can be obtained from a plot of $\ln \ln \left(1 / 1-\mathrm{P}_{\mathrm{f}}\right)$ versus $\ln \sigma$ (commonly referred to as a Weibull plot) which should produce a straight line, with gradient $w$ and intercept $\sigma_{0}$ at $\ln \ln \left(1 / 1-\mathrm{P}_{\mathrm{f}}\right)=0$.

\section{Wide Angle X-ray Diffraction}

A Philips X'Pert diffractometer fitted with a ceramic X-ray diffraction tube was used to assess the influence of alkali treatment on fibre crystallinity. Prior to the 
analysis, untreated and treated harakeke and hemp fibres were cut by hand into fine particles and compressed into disks using a cylindrical steel mould with appropriate amount of pressure. The diffracted intensity of $\mathrm{CuK} \alpha$ radiation $(\lambda=1.54 \mathrm{~nm})$ was recorded between $12^{\circ}$ and $30^{\circ}(2 \theta$-angle range) using a current and voltage of $40 \mathrm{~mA}$ and $40 \mathrm{mV}$ with scanning speed of 0.02 degrees/second. The percentage crystallinity index $\left(I_{c}\right)$ was then determined using the Segal empirical method according to the following equation $[20,21]$ :

$I_{C}=\frac{\left(I_{002}-I_{a m}\right)}{I_{002}} \times 100$

where $I_{002}$ is the maximum intensity of diffraction of the lattice peak at a $2 \theta$-angle of between $22^{\circ}$ and $23^{\circ}$ and $I_{a m}$ is the intensity of diffraction of the amorphous material, which is taken at a $2 \theta$-angle between $18^{\circ}$ and $19^{\circ}$ where the intensity is at a minimum $[22,23]$.

\section{Thermal Analysis}

Untreated and treated fibre samples weighing between 8 and $12 \mathrm{mg}$ were analysed using an SDT 2960 Simultaneous DTA-TGA analyser. The analysis was operated in a dynamic mode, heating from ambient temperature to $500^{\circ} \mathrm{C}$ at $10^{\circ} \mathrm{C} / \mathrm{min}$ in air purged at $150 \mathrm{ml} / \mathrm{min}$ with an empty pan used as a reference. Differential thermal analysis (DTA) and thermal gravimetric analysis (TGA) curves were obtained at the end of the operation.

\section{Results and Discussion}

\section{Scanning Electron Microscopy}

SEM micrographs of harakeke fibres are shown in Figure 4 to Figure 6 and hemp in Figures 7 and 8. As can be seen in Figure 4a, untreated harakeke fibre bundles were composed of many single fibres attached to each other and coated with substances known to include hemicellulose, pectin, lignin, and other non-strengthening components 
[21]. In contrast, alkali treated harakeke fibres (shown Figure 5 and 6) were separated from each other and appeared to have undergone removal of surface coating revealing less rounded sides and a rougher texture with a large numbers of grooves, believed to be cellulose rich as seen for treatment of other cellulosic fibres [24-26]. The fibre separation resulting from the removal of non-strengthening components along with the exposure of rougher texture would have increased contact area for bonding and could therefore be expected to improve fibre-matrix interfacial bonding. The improvement of fibre-matrix adhesion is also expected due to the exposure of more cellulose $\mathrm{OH}$ groups, which could bond with reactive sites on the matrix [24]. Likewise for hemp, all treated fibre was well separated and surfaces appeared to have increased overall rugosity compared to the untreated fibre as shown in Figure 7(b) and Figure 8.

\section{Single Fibre Tensile Testing}

Alkali treatment of cellulosic fibres using $\mathrm{NaOH}$ and $\mathrm{Na}_{2} \mathrm{SO}_{3}$ is widely used in the pulp and paper industry to separate single fibres from their bundles and as mentioned previously has also been shown to remove non-reinforcing components and can improve the fibre properties, although overtreatment can decrease fibre properties significantly [27-30]. Ideally alkali treatment should separate fibres, improve fibre dispersion within composites and offer an improvement to the fibre properties [31].

As can be seen in Table 3, the harakeke fibres were a lot finer than hemp fibres (as seen in optical micrographs) and were not quite as strong but stiffer. Alkali treatments resulted in a decrease of fibre diameter for both harakeke and hemp fibres, which can be attributed to the removal of alkali-soluble components from the fibre cell walls. For the treatments using $\mathrm{NaOH}$ only, the reduction in diameter for hemp and harakeke fibre was found to correspond to the severity of the treatment used, considered to be simply due to more alkali-soluble components removed from the fibre at higher alkali concentration. The diameter of harakeke reduced by $5.8 \%$ and $12.2 \%$ and that for 
hemp reduced by $16.3 \%$ and $16.8 \%$ when treated using $5 \mathrm{wt} \% \mathrm{NaOH}$ and $10 \mathrm{wt} \% \mathrm{NaOH}$ solutions respectively. Treatment using $5 \mathrm{wt} \% \mathrm{NaOH} / 2 \mathrm{wt} \% \mathrm{Na}_{2} \mathrm{SO}_{3}$ was found to give maximum reduction in diameter for both fibres. The reductions in fibre diameter for harakeke and hemp treated with this solution were found to be 13.8 and $18.9 \%$ respectively. Addition of $\mathrm{Na}_{2} \mathrm{SO}_{3}$ has been shown elsewhere to assist $\mathrm{NaOH}$ in the removal of lignin and shorten treatment times required [32-34]. These effects are facilitated when sulphite groups $\left(\mathrm{SO}_{2}{ }^{-3}\right)$ in the $\mathrm{Na}_{2} \mathrm{SO}_{3}$ are introduced into the lignin side chains by means of sulphonation, and enable the lignin to be quickly dissolved into the alkaline solution $[12,35]$. Although no specific analysis was conducted to measure the lignin content of treated fibres in this study, it is proven elsewhere that lignin was effectively removed by the application of $\mathrm{Na}_{2} \mathrm{SO}_{3}$ [28]. It was found that treatment with $10 \mathrm{wt} \% \mathrm{NaOH}$ removed sufficient hemicellulose and pectin from hemp fibre to give good fibre separation, but similar separation was not obtained with $10 \mathrm{wt} \% \mathrm{NaOH}$ for harakeke as harakeke contains greater amount of lignin compared to hemp [12]. However, good separation was achieved for harakeke using $2 \mathrm{wt} \% \mathrm{Na}_{2} \mathrm{SO}_{3}$ with $5 \mathrm{wt} \%$ $\mathrm{NaOH}$ at the higher temperature and longer processing time required to remove a greater amount of lignin.

Reduction in average tensile strength was observed for all treated harakeke and hemp fibres. Tensile strength of harakeke and hemp fibres reduced dramatically, up to nearly $30 \%$ relative to untreated fibres when treated with $10 \mathrm{wt} \% \mathrm{NaOH}$ solution. The smallest reduction for treated harakeke and hemp fibres were 3 and $15.4 \%$ when treated using $5 \mathrm{wt} \% \mathrm{NaOH} / 2 \mathrm{wt} \% \mathrm{Na}_{2} \mathrm{SO}_{3}$ and $5 \mathrm{wt} \% \mathrm{NaOH}$ respectively. However, this reduction was found to be insignificant when the tensile strength data was analysed using a one-tailed Student's t-test and given that fibre separation had occurred, these were considered useful treatments. That different treatment should be required for hemp and harakeke is not surprising given the higher levels of non-cellulosic components 
removal in harakeke leading to the requirement of a higher concentration of alkali even when conducted at higher temperature and for a longer time.

Also from Table 3, Young's modulus can be seen to increase or decrease dependent on the treatment used. The average Young's modulus for treated harakeke fibres reduced by $1.54 \%$ and $10.0 \%$ when treated with $5 \mathrm{wt} \% \mathrm{NaOH}$ and $10 \mathrm{wt} \% \mathrm{NaOH}$ but increased by $2.36 \%$ when treated with $5 \mathrm{wt} \% \mathrm{NaOH} / 2 \mathrm{wt} \% \quad \mathrm{Na}_{2} \mathrm{SO}_{3}$. Statistical analysis did not support a significant reduction in Young's modulus of treated hemp fibres when compared with those of the untreated fibres, although high variability of data was observed considering experimental errors which at some level have influenced the variability in calculated values [30]. Surprisingly for hemp, the Young's modulus for all treated fibres was improved with treatment; treatment using $10 \mathrm{wt} \% \mathrm{NaOH}$ improved the Young's modulus the most, (by 37.9\%) and was found significant as suggested by the Student's t-test. The increment in Young's modulus could be due to improvement in cellulose rigidity resulting in removal of non-cellulosic components. Taking into consideration the desire for fibre separation as well as strength, harakeke fibre treated with $5 \mathrm{wt} \% \mathrm{NaOH} / 2 \mathrm{wt} \% \mathrm{Na}_{2} \mathrm{SO}_{3}$ was selected along with hemp fibre treated with $5 \mathrm{wt} \% \mathrm{NaOH}$ for further study.

The tensile strength of fibres was further statistically analysed using the Weibull cumulative distribution through linear regression and applying the estimator in equation 2. Weibull characteristic strength and Weibull modulus are tabulated in Table 4. It is worthy of note that the two-parameter Weibull distribution approximated the experimental data relatively well, particularly for alkali treated fibres. As expected, Weibull characteristic strength has the same trend as the average tensile strength. Bearing in mind that natural fibres generally possess much larger property variability than commercially produced synthetic fibres in terms mechanical, physical, and chemical properties, low Weibull modulus representing a high distribution of fibre 
strength was expected as is seen here. From Table 4, it can be seen that, Weibull modulus for harakeke fibre varied from 2.43 to 4.88 and from 1.75 to 3.00 for hemp fibre with the lowest Weibull modulus observed in untreated harakeke and hemp fibres. These values are comparable with those from other authors for cellulosic fibres $[18,29$, 36-38]. The lower Weibull moduli values for untreated fibre may be explained by the fact that the untreated fibre is larger in diameter having a bigger volume and therefore is more likely to contain more defects.

\section{Wide Angle X-ray Diffraction}

For most cellulosic fibres, peaks for crystalline phases are normally observed at around $2 \theta=15,17$ and $20^{\circ}$ (denoted as peaks 1,2 and 3 respectively as shown in Figure 9) which represent the cellulose crystallographic planes (110), (11i0) and (002). The amorphous phase peak (denoted as peak 4) was assigned according to the current literature [39] at the lowest point between peaks 2 and 3 (for (002) and (11̄0) planes). Generally, it is found in studies that cellulose crystallographic (002) planes are clearly represented, however, the cellulose crystallographic plane peaks of (110) and (11i0) are only clearly seen separately when the cellulose content is high [40], but when the fibre contains high amounts of amorphous material, these two peaks overlap and appear as one broad peak [21, 41].

The X-ray diffractograms of untreated, $\mathrm{NaOH}$ treated and $\mathrm{NaOH} / \mathrm{Na}_{2} \mathrm{SO}_{3}$ treated harakeke and hemp fibres are shown in Figure 10 and Figure 11. As expected, major crystalline peaks for harakeke and hemp fibres occurred at $2 \theta$ around $22^{\circ}$. It can be seen that intensity of the (002) crystallographic plane peak increased significantly as a result of alkali treatment suggesting removal of amorphous material [22, 30]. Other peaks were present on the X-ray diffractograms for harakeke and hemp fibre at $2 \theta$ around 15 and $17^{\circ}$, which represent the cellulose crystallographic planes of (110) and (11̄0) 
respectively. These peaks can be clearly observed individually for all treated hemp fibre but only with treatment using $10 \mathrm{wt} \% \mathrm{NaOH}$ for harakeke. Although the (002) peak is not the highest for harakeke treated with $10 \mathrm{wt} \% \mathrm{NaOH}$, it is the peak areas that give most accurate information on crystallinity on which crystallinity index is established. The values of crystallinity index $\left(I_{c}\right)$ for treated and untreated harakeke and hemp fibres are presented in Table 5. The values of crystallinity index $\left(I_{c}\right)$ were calculated using Equation 4 considering the peaks for the crystalline (peak 3) and the amorphous (peak 4) phases as depicted in Figure 9 [39]. It should be noted that the crystallinity index is generally used for comparison rather than to define absolute crystallinity [28]. As can be seen in the presented results, the crystallinity index $\left(I_{c}\right)$ of harakeke and hemp fibres was effectively increased by alkali treatment. The crystallinity index $\left(I_{c}\right)$ of treated fibres was increased up to $20 \%$ (using $10 \mathrm{wt} \% \mathrm{NaOH}$ solution) for harakeke and $15 \%$ (using $5 \mathrm{wt} \% \mathrm{NaOH}$ solution) for hemp with low variation between treated fibres. Such behaviour is expected, as under the applied treatment, amorphous materials (e.g. lignin, hemicellulose and wax) would be removed from the fibres [20, 29].

Increase in fibre crystallinity with alkali treatment has also been suggested to occur due to better packing and stress relaxation of cellulose chains. However, the removal of excessive amounts of amorphous materials can possibly reduce the tensile strength by loss of adhesion between cellulose microfibrils [22].

\section{Thermal Analysis}

The TGA and DTA thermograms for harakeke and hemp fibres are shown in Figure 12 and 13 respectively. The thermal degradation of harakeke and hemp fibre can be identified by reduction in sample weight in TGA themograms and a temperature difference in DTA thermograms. This was evidenced as starting at around $70^{\circ} \mathrm{C}$ for harakeke and hemp fibre when it is believed there is evolution of adsorbed moisture from the fibres. The fibre weight was then maintained until a reduction at around $250^{\circ} \mathrm{C}$ 
for untreated fibre and around $300^{\circ} \mathrm{C}$ for treated fibre, which has been associated with the initial thermal depolymerisation traces of hemicellulose and pectin followed by cellulose [42]. This stage was completed when the temperature reached around $345^{\circ} \mathrm{C}$ for harakeke and $355^{\circ} \mathrm{C}$ for hemp when the fibres had lost almost $60 \%$ for untreated and $80 \%$ for treated fibre of their initial weight. The final stage of thermal degradation occurred at temperatures between 400 to $450^{\circ} \mathrm{C}$ when the fibres had lost almost $95 \%$ of their initial weight leaving behind ash and unburnt minerals [28, 43]. The weight loss of untreated and treated fibres at different stages of thermal degradation is presented in Table 6. It can be seen that the degradation temperatures at different stages of thermal degradation for treated fibres were consistently higher than for untreated fibres indicating the heat resistance of fibre was effectively improved by alkali treatment [44].

DTA thermograms (Figure 12(b) and 13(b)) support the different stages of moisture loss and decomposition at the same temperatures as those evaluated by weight lost. Two main peaks were observed for all hemp and harakeke fibres, however, narrower peaks can clearly be observed for treated fibre, representing a more homogeneous cellulose content than for untreated fibre [45].

\section{CONCLUSIONS}

Compared to hemp fibre, harakeke fibre was found to be $25 \%$ weaker in its untreated state and required a harsher treatment to bring about fibre separation, which is believed to be due to the higher quantity of lignin in its composition. However, with a strength of $782 \mathrm{MPa}$ it would generally be expected to provide significant reinforcement in most common polymer matrices. Treatment with $\mathrm{NaOH}$ and $\mathrm{Na}_{2} \mathrm{SO}_{3}$ was found to improve separation and remove surface constituents for harakeke as well as hemp fibre. As a consequence of constituent removal, fibre diameter, maximum tensile load and tensile strength were found to decrease in most cases. However, it was found that the 
tensile strength of hemp fibre treated with $5 \mathrm{wt} \% \mathrm{NaOH}$ and harakeke fibre treated with $5 \mathrm{wt} \% \mathrm{NaOH} / 2 \mathrm{wt} \% \mathrm{Na}_{2} \mathrm{SO}_{3}$ was not significantly affected as confirmed by a Student's ttest, although the average tensile strength suggests a slight reduction. It was also found that the crystallinity index $\left(I_{c}\right)$ for all treated fibres increased significantly compared to untreated fibres. Furthermore, the application of alkali treatment was also found to lead to better thermal stability resulting in more homogeneous cellulose content as indicated with narrower peaks in DTA thermograms.

\section{FUNDING ACKNOWLEDGEMENT}

This research received no specific grant from any funding agency in the public, commercial, or not-for-profit sectors. However, the author would like to thank to the Composites Research Group, University of Waikato for their support and the Ministry of Education and Universiti Teknologi Mara Malaysia for the scholarship. The authors also would like to thank The Hemp Farm, especially Mr Dave Jordan, for supply of materials and their ongoing support of research in natural fibre composites.

\section{REFERENCES}

[1] Burgueno R, Quagliata MJ, Mehta GM, Mohanty AK, Misra M, Drzal LT. Sustainable cellular biocomposites from natural fibers and unsaturated polyester resin for housing panel applications. Journal of Polymers and the Environment. 2005;13(2):139-49.

[2] Dittenber DB, GangaRao HVS. Critical Review of Recent Publications on Use of Natural Composites in Infrastructure. Composites Part A: Applied Science and Manufacturing. 2011.

[3] Stamboulis A, Baillie C, Garkhail S, Van Melick H, Peijs T. Environmental durability of flax fibres and their composites based on polypropylene matrix. Applied Composite Materials. 2000;7(5):273-94.

[4] Bodros E, Pillin I, Montrelay N, Baley C. Could biopolymers reinforced by randomly scattered flax fibre be used in structural applications? Composites Science and Technology. 2007;67(3):462-70.

[5] Brouwer W. Natural fibre composites: where can flax compete with glass? Sampe Journal. 2000;36(6):18-23. 
[6] Dweib M, Hu B, O'donnell A, Shenton H, Wool R. All natural composite sandwich beams for structural applications. Composite structures. 2004;63(2):147-57.

[7] Satyanarayana K, Sukumaran K, Kulkarni A, Pillai S, Rohatgi P. Fabrication and properties of natural fibre-reinforced polyester composites. Composites. 1986;17(4):329-33.

[8] Wambua P, Ivens J, Verpoest I. Natural fibres: can they replace glass in fibre reinforced plastics? Composites Science and Technology. 2003;63(9):1259-64.

[9] Sawpan MA. Mechanical Performance of Industrial Hemp Fibre Reinforced Polylactide and Unsaturated Polyester Composites: The University of Waikato; 2010.

[10] De Rosa IM, Kenny JM, Puglia D, Santulli C, Sarasini F. Tensile behavior of New Zealand flax (Phormium tenax) fibers. Journal of Reinforced Plastics and Composites. 2010;29(23):3450-4.

[11] Jayaraman K, Halliwell R. Harakeke (phormium tenax) fibre-waste plastics blend composites processed

by screwless extrusion. Composites Part B: Engineering. 2009;40(7):645-9.

[12] Fortunati E, Puglia D, Monti M, Peponi L, Santulli C, Kenny J, et al. Extraction of cellulose nanocrystals from Phormium tenax fibres. Journal of Polymers and the Environment. 2013;21(2):319-28.

[13] Duchemin B, Staiger MP. Treatment of Harakeke fiber for biocomposites. Journal of applied polymer science. 2009;112(5):2710-5.

[14] Le Guen MJ, Newman RH. Pulped Phormium tenax leaf fibres as reinforcement for epoxy composites. Composites Part A: Applied Science and Manufacturing. 2007;38(10):2109-15.

[15] Newman RH, Clauss EC, Carpenter JEP, Thumm A. Epoxy composites reinforced with deacetylated Phormium tenax leaf fibres. Composites Part A: Applied Science and Manufacturing. 2007;38(10):2164-70.

[16] D A. Standard test method for tensile strength and Young's Modulus for high-modulus single-filament materials. 1989.

[17] Weibull W. A statistical distribution function of wide applicability. Journal of applied mechanics. 1951;18(3):293-7.

[18] Zafeiropoulos N, Baillie C. A study of the effect of surface treatments on the tensile strength of flax fibres: Part II. Application of Weibull statistics. Composites Part A: Applied Science and Manufacturing. 2007;38(2):629-38.

[19] Biagiotti J, Puglia D, Torre L, Kenny JM, Arbelaiz A, Cantero G, et al. A systematic investigation on the influence of the chemical treatment of natural fibers on the properties of their polymer matrix composites. Polymer Composites. 2004;25(5):470-9.

[20] Mwaikambo LY, Ansell MP. Chemical modification of hemp, sisal, jute, and kapok fibers by alkalization. Journal of applied polymer science. 2002;84(12):2222-34.

[21] Tserki V, Zafeiropoulos N, Simon F, Panayiotou C. A study of the effect of acetylation and propionylation surface treatments on natural fibres. Composites Part A: Applied Science and Manufacturing. 2005;36(8):1110-8.

[22] Beckermann G, Pickering KL. Engineering and evaluation of hemp fibre reinforced polypropylene composites: fibre treatment and matrix modification. Composites Part A: Applied Science and Manufacturing. 2008;39(6):979-88.

[23] Roncero MB, Torres AL, Colom JF, Vidal T. The effect of xylanase on lignocellulosic components during the bleaching of wood pulps. Bioresource technology. 2005;96(1):21-30.

[24] Le Troedec M, Sedan D, Peyratout C, Bonnet JP, Smith A, Guinebretiere R, et al. Influence of various chemical treatments on the composition and structure of hemp fibres. Composites Part A: Applied Science and Manufacturing. 2008;39(3):514-22.

[25] Mehta G, Mohanty AK, Thayer K, Misra M, Drzal LT. Novel biocomposites sheet molding compounds for low cost housing panel applications. Journal of Polymers and the Environment. 2005;13(2):169-75.

[26] Ouajai S, Shanks RA. Morphology and structure of hemp fibre after bioscouring. Macromolecular bioscience. 2005;5(2):124-34. 
[27] Beckermann G. Performance of hemp-fibre reinforced polypropylene composite materials: The University of Waikato; 2007.

[28] Islam MS, Pickering KL, Foreman NJ. Influence of alkali fiber treatment and fiber processing on the mechanical properties of hemp/epoxy composites. Journal of applied polymer science. 2011;119(6):3696-707.

[29] Pickering K, Beckermann G, Alam S, Foreman N. Optimising industrial hemp fibre for composites. Composites Part A: Applied Science and Manufacturing. 2007;38(2):461-8.

[30] Sawpan MA, Pickering KL, Fernyhough A. Effect of various chemical treatments on the fibre structure and tensile properties of industrial hemp fibres. Composites Part A: Applied Science and Manufacturing. 2011;42(8):888-95.

[31] Kabir M, Wang H, Lau K, Cardona F. Chemical treatments on plant-based natural fibre reinforced polymer composites: An overview. Composites Part B: Engineering. 2012.

[32] Bismarck A, Aranberri-Askargorta I, Springer J, Lampke T, Wielage B, Stamboulis A, et al. Surface characterization of flax, hemp and cellulose fibers; surface properties and the water uptake behavior. Polymer Composites. 2002;23(5):872-94.

[33] Rai A, Jha C. Natural fibre composites and its potential as building materials. Express Textile. 2004;25.

[34] Shahzad A. Hemp fiber and its composites-a review. Journal of Composite Materials. 2012;46(8):973-86.

[35] Wang H, Postle R, Kessler R, Kessler W. Removing pectin and lignin during chemical processing of hemp for textile applications. Textile Research Journal. 2003;73(8):664-9.

[36] Doan T-T-L, Gao S-L, Mäder E. Jute/polypropylene composites I. Effect of matrix modification. Composites Science and Technology. 2006;66(7):952-63.

[37] Joffe R, Andersons J, Wallström L. Strength and adhesion characteristics of elementary flax fibres with different surface treatments. Composites Part A: Applied Science and Manufacturing. 2003;34(7):603-12.

[38] Xia Z, Yu J, Cheng L, Liu L, Wang W. Study on the breaking strength of jute fibres using modified Weibull distribution. Composites Part A: Applied Science and Manufacturing. 2009;40(1):54-9.

[39] Oraji R. The effect of plasma treatment on flax fibres: University of Saskatchewan; 2008.

[40] Wang B, Sain M, Oksman K. Study of structural morphology of hemp fiber from the micro to the nanoscale. Applied Composite Materials. 2007;14(2):89-103.

[41] Ouajai S, Shanks R. Composition, structure and thermal degradation of hemp cellulose after chemical treatments. Polymer degradation and stability. 2005;89(2):327-35.

[42] Islam M, Pickering K, Foreman N. Influence of alkali treatment on the interfacial and physico-mechanical properties of industrial hemp fibre reinforced polylactic acid composites. Composites Part A: Applied Science and Manufacturing. 2010;41(5):596-603.

[43] Luyt A, Mokhothu T, Guduri B. Kenaf-fiber-reinforced copolyester biocomposites. Wiley Online Library. 2011.

[44] Shih Y-F, Huang C-C. Polylactic acid (PLA)/banana fiber (BF) biodegradable green composites. Journal of Polymer Research. 2011;18(6):2335-40.

[45] Gañán P, Mondragon I. Surface modification of fique fibers. Effect on their physicomechanical properties. Polymer Composites. 2002;23(3):383-94.

\section{FIGURE CAPTIONS}

Figure 1: Schematic diagram of cardboard used in testing with mounted single

fibre.

Figure 2: Single harakeke fibre as observed under optical microscope. 
Figure 3: Single hemp fibre as observed under optical microscope.

Figure 4: Scanning electron micrographs of untreated harakeke: (a) in bundle form, (b) a mechanically separated single fibre.

Figure 5: Scanning electron micrographs of treated harakeke fibre surface using: (a) $5 \mathrm{wt} \% \mathrm{NaOH}$ and (b) $10 \mathrm{wt} \% \mathrm{NaOH}$.

Figure 6: Scanning electron micrograph of treated harakeke fibre surface using $5 w t \% \mathrm{NaOH} / 2 \mathrm{wt}_{\%} \mathrm{Na}_{2} \mathrm{SO}_{3}$.

Figure 7: Scanning electron micrographs of (a) untreated hemp and (b) $5 w t \%$ $\mathrm{NaOH}$ treated fibre surface.

Figure 8: Scanning electron micrographs of treated hemp fibre surface using: (a) $10 \mathrm{wt} \% \mathrm{NaOH}$ and (b) $5 \mathrm{wt} \% \mathrm{NaOH} / 2 \mathrm{wt} \% \mathrm{Na} 2 \mathrm{SO}$.

Figure 9: Typical diffraction curves of natural fibres used in calculating crystallinity index by the area method.

Figure 10: X-ray diffraction curves for untreated and treated harakeke fibres. Figure 11: X-ray diffraction curves for untreated and treated hemp fibres. Figure 12: (a) TGA thermograms for untreated and treated harakeke fibres Figure 12: (b) DTA thermograms for untreated and treated harakeke fibres. Figure 13: (a) TGA thermograms for untreated and treated hemp fibres. Figure 13: (b) DTA thermograms for untreated and treated hemp fibres.

\section{TABLE CAPTIONS}

Table 1: Chemical composition of harakeke fibre Table 2: Abbreviations used for fibre and treatment

Table 3: Mechanical properties of untreated and alkali treated fibres. Standard deviations are included in parenthesis. 
Table 4: Experimental tensile strength and Weibull parameters of untreated and alkali treated fibres.

Table 5: Crystallinity index $\left(I_{c}\right)$ of untreated and alkali treated harakeke and hemp fibres

Table 6: Summary of TGA results for untreated and treated harakeke and hemp fibres. 


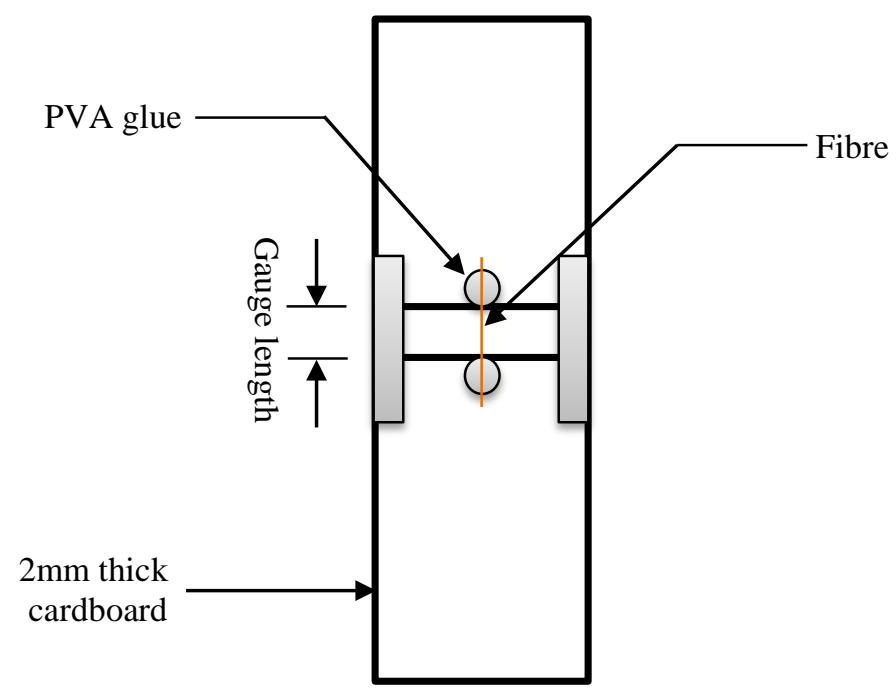

Figure 1: Schematic diagram of cardboard used in testing with mounted single fibre.

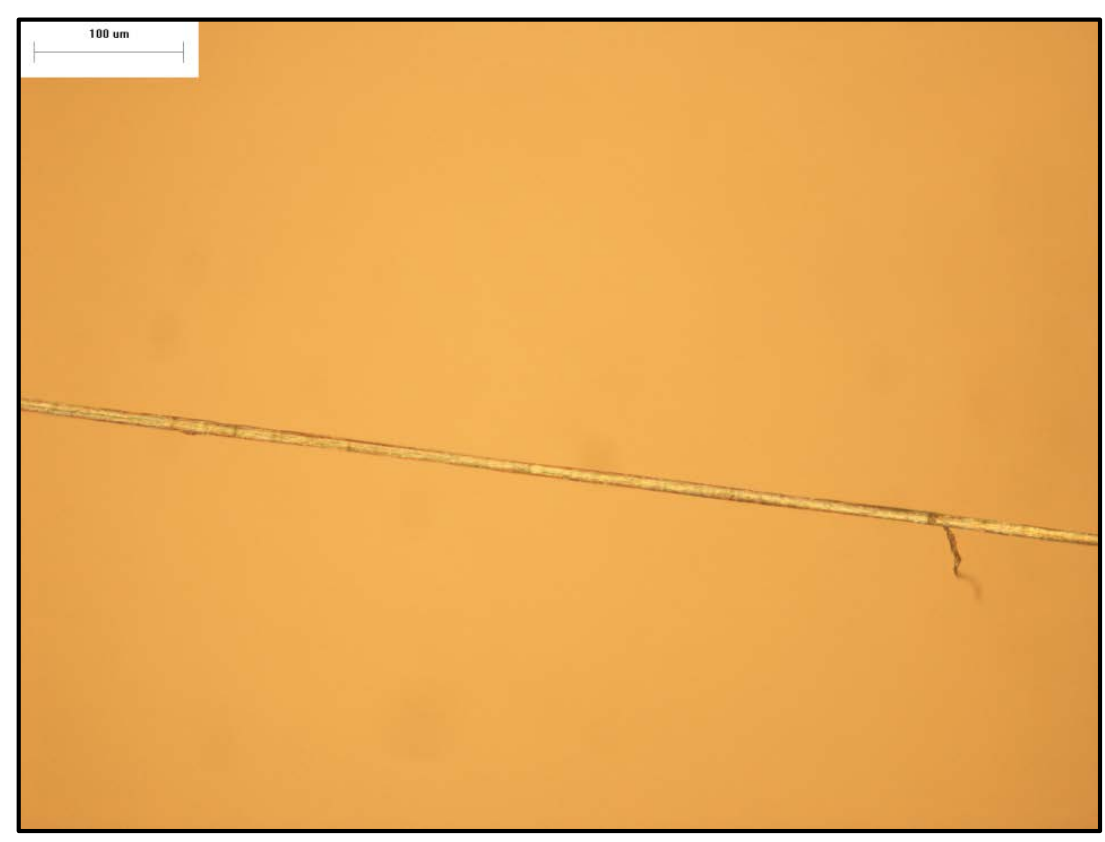

Figure 2: Single harakeke fibre as observed under optical microscope. 


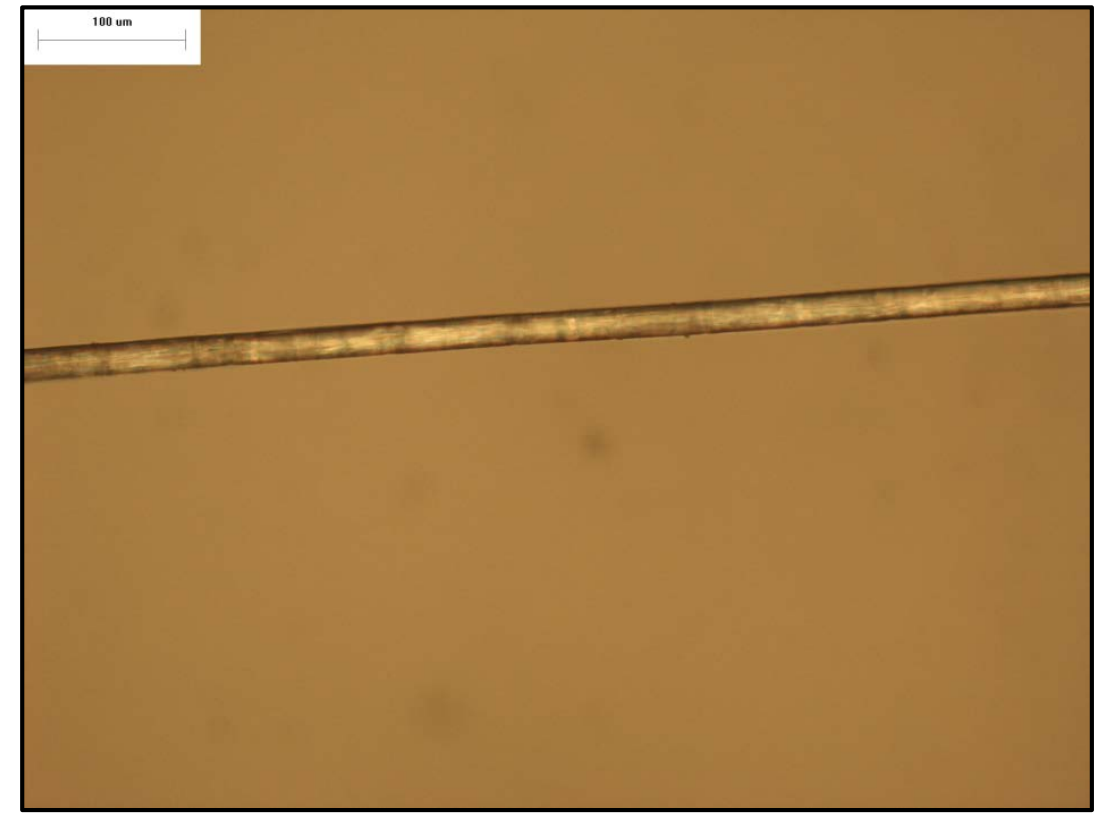

Figure 3: Single hemp fibre as observed under optical microscope.

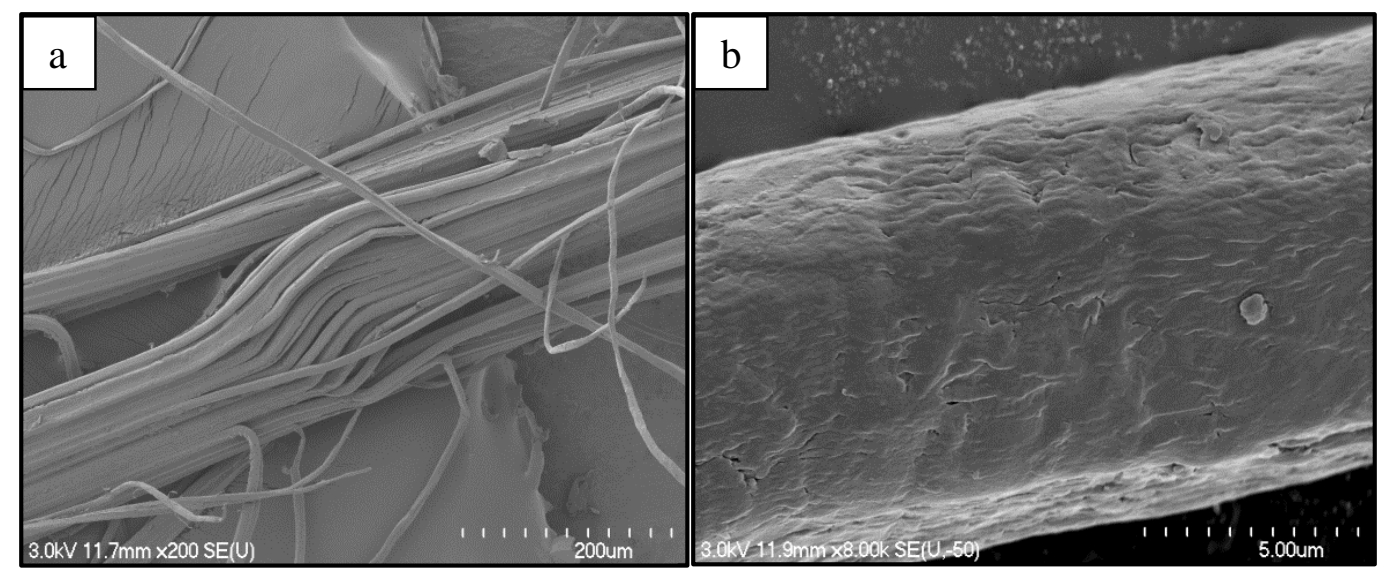

Figure 4: Scanning electron micrographs of untreated harakeke: (a) in bundle form, (b) a mechanically separated single fibre. 


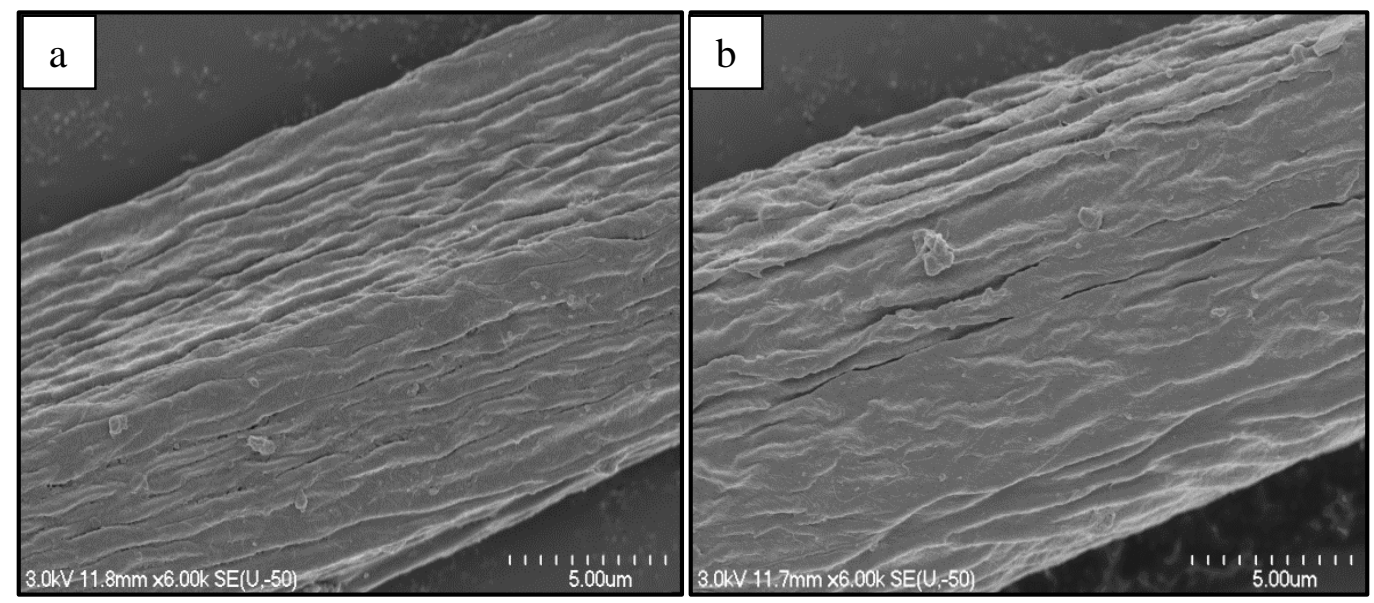

Figure 5: Scanning electron micrographs of treated harakeke fibre surface using: (a) $5 \mathrm{wt} \% \mathrm{NaOH}$ and (b) $10 \mathrm{wt} \% \mathrm{NaOH}$.

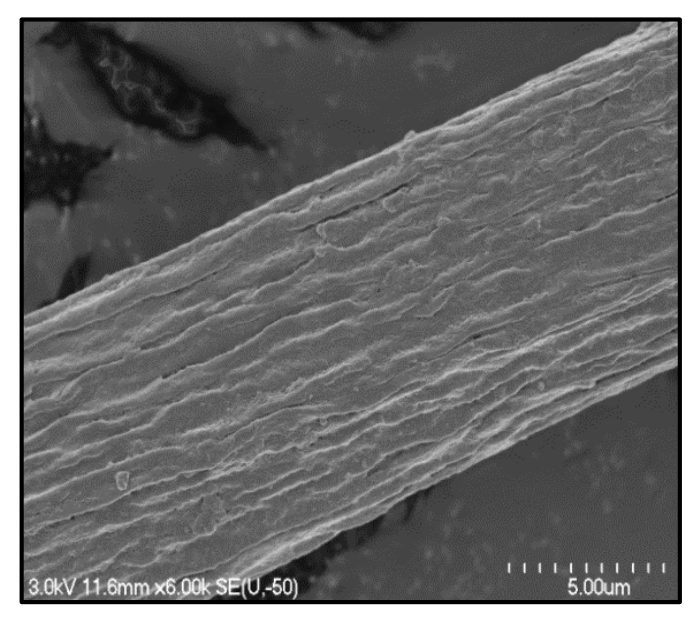

Figure 6: Scanning electron micrograph of treated harakeke fibre surface using $5 \mathrm{wt} \% \mathrm{NaOH} / 2 \mathrm{wt} \%$ $\mathrm{Na}_{2} \mathrm{SO}_{3}$. 


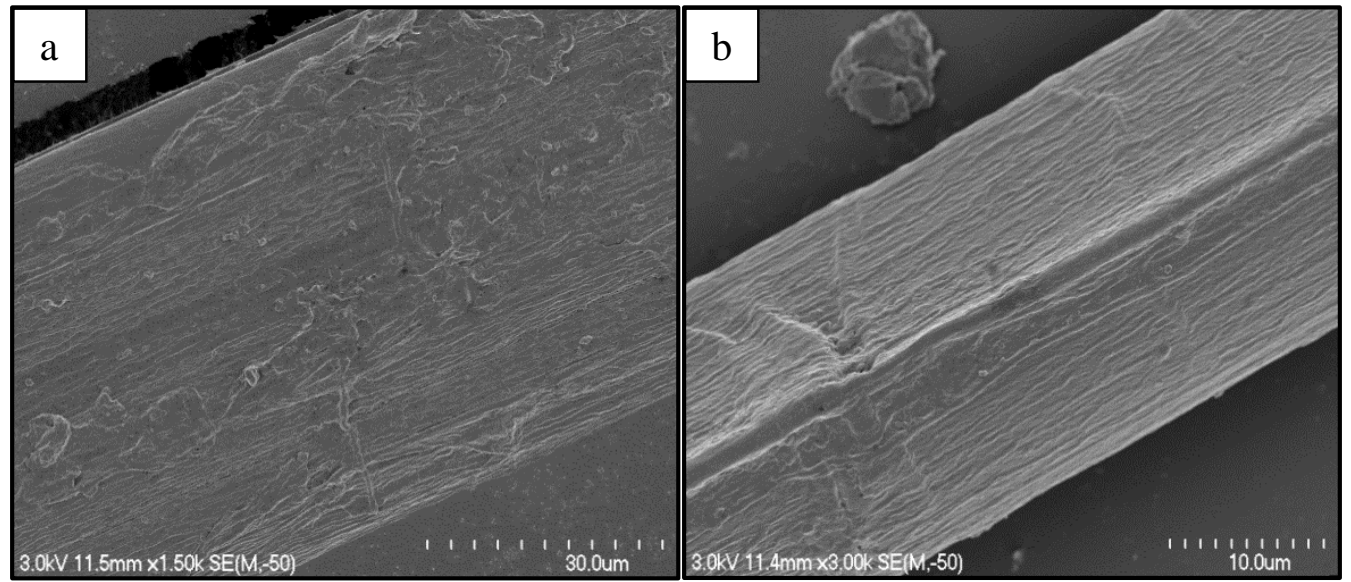

Figure 7: Scanning electron micrographs of (a) untreated hemp and (b) $5 \mathrm{wt} \% \mathrm{NaOH}$ treated fibre surface.

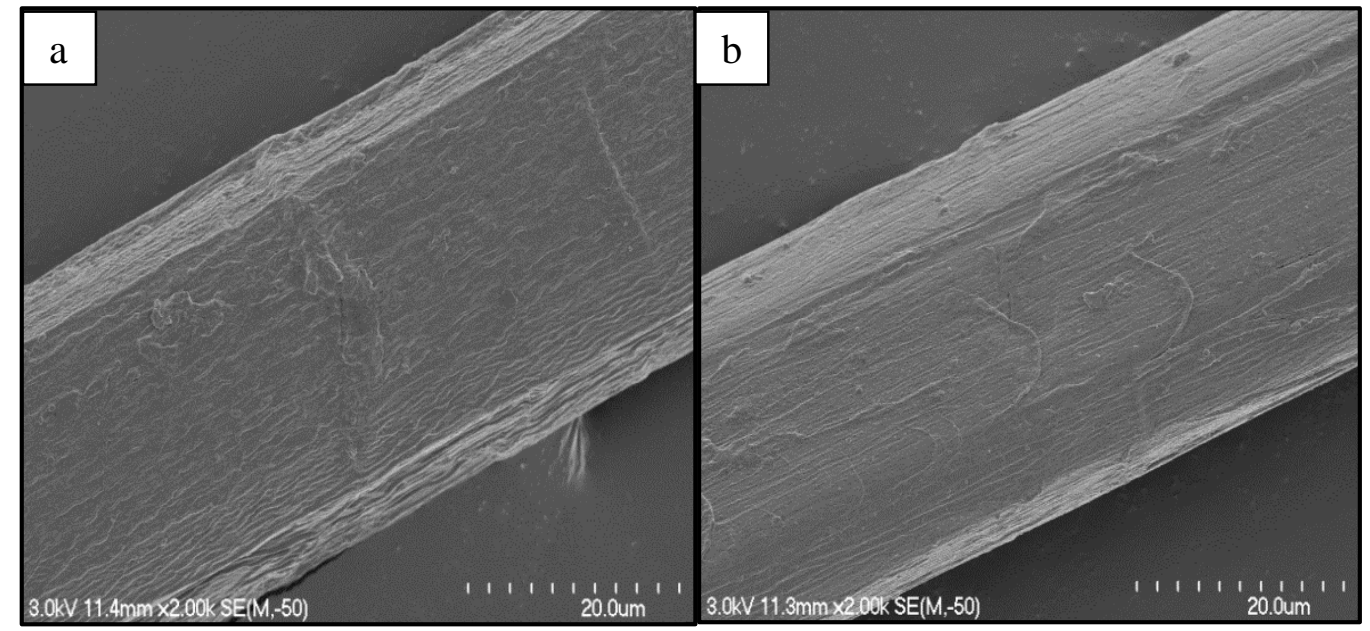

Figure 8: Scanning electron micrographs of treated hemp fibre surface using: (a) 10wt $\% \mathrm{NaOH}$ and (b) $5 \mathrm{wt} \% \mathrm{NaOH} / 2 \mathrm{wt} \% \mathrm{Na}_{2} \mathrm{SO}_{3}$. 




Diffraction angle $2 \theta\left(^{\circ}\right)$

Figure 9: Typical diffraction curves of natural fibres used in calculating crystallinity index by the area method.

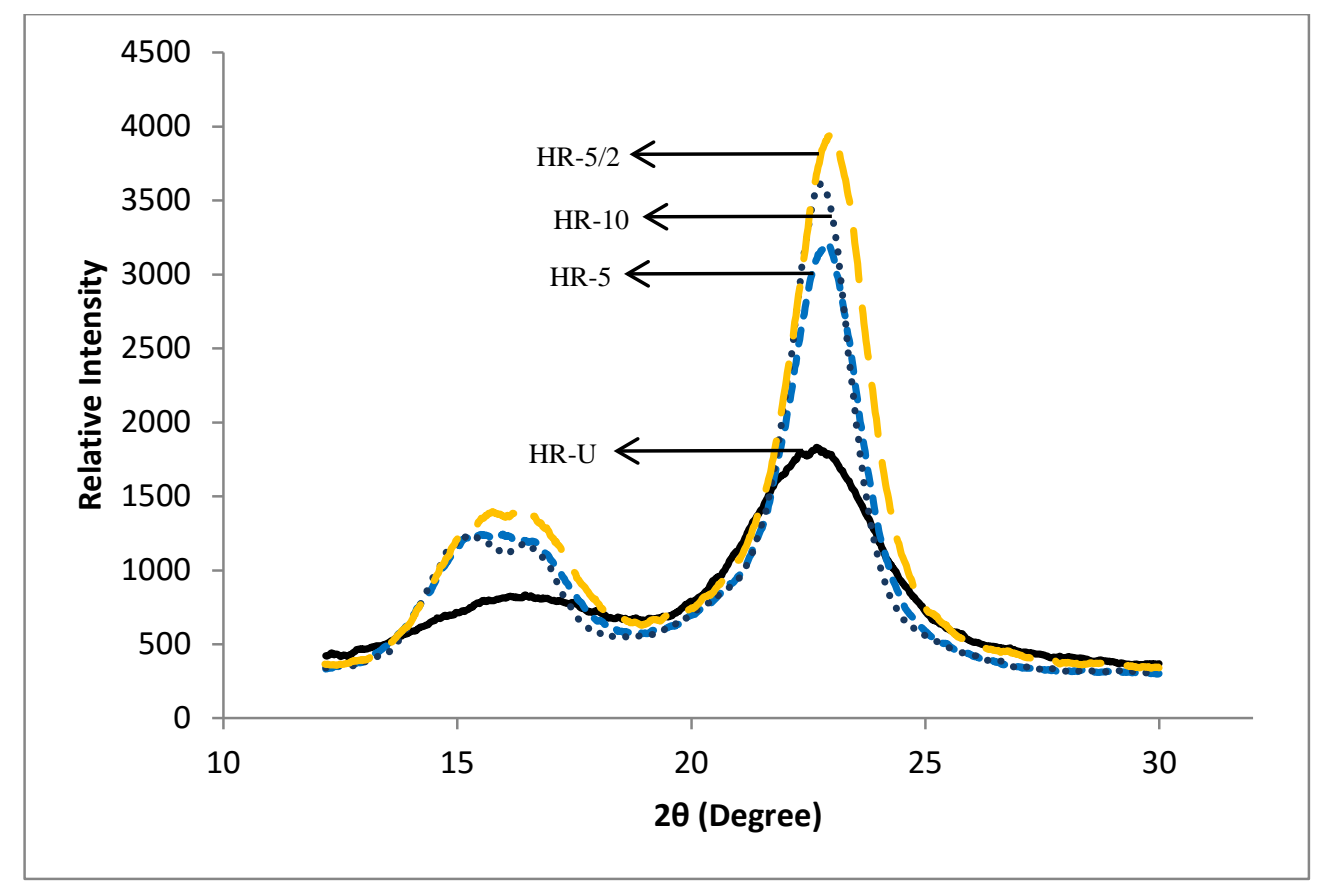

Figure 10: X-ray diffraction curves for untreated and treated harakeke fibres. 




Figure 11: X-ray diffraction curves for untreated and treated hemp fibres.

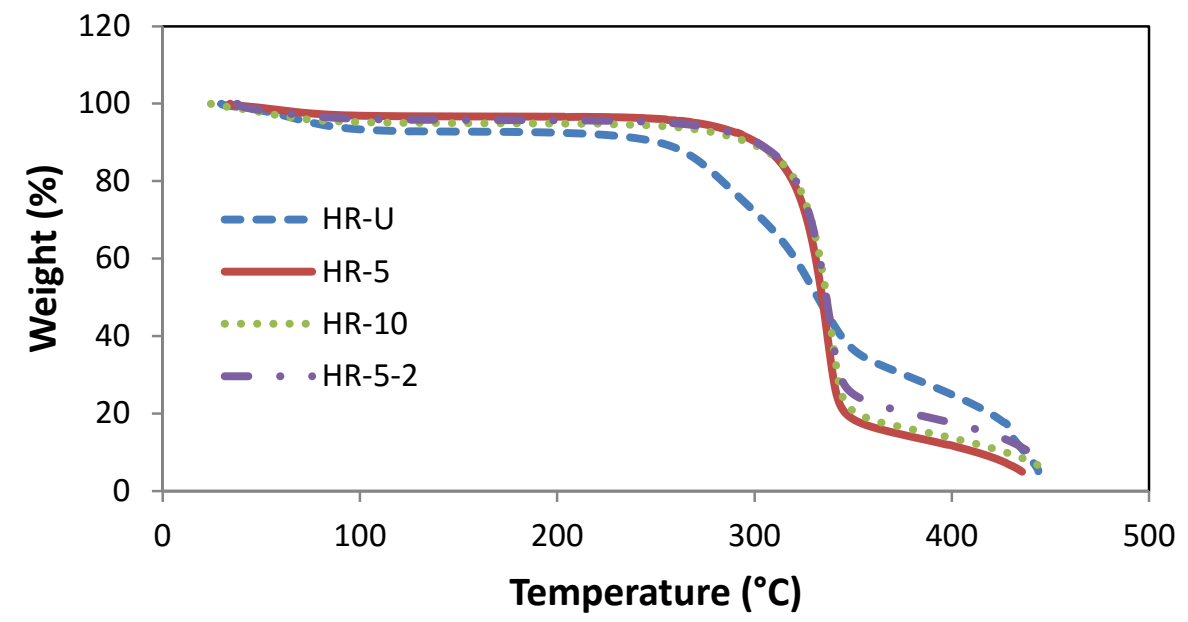

Figure 12: (a) TGA thermograms for untreated and treated harakeke fibres. 


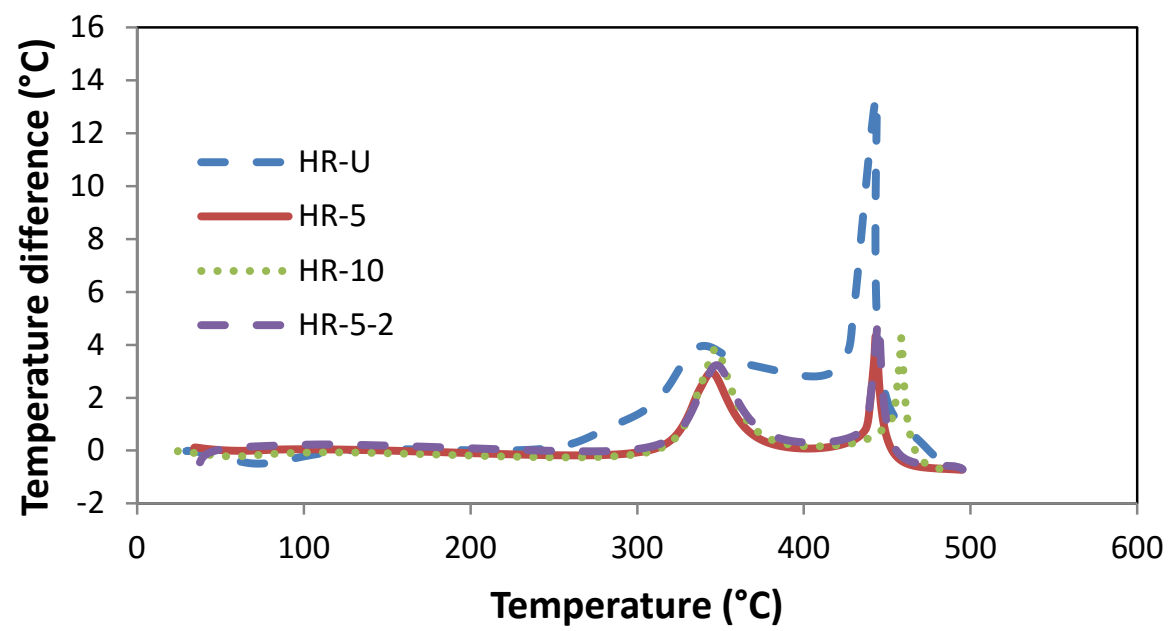

Figure 12: (b) DTA thermograms for untreated and treated harakeke fibres.



Figure 13: (a) TGA thermograms for untreated and treated hemp fibres. 


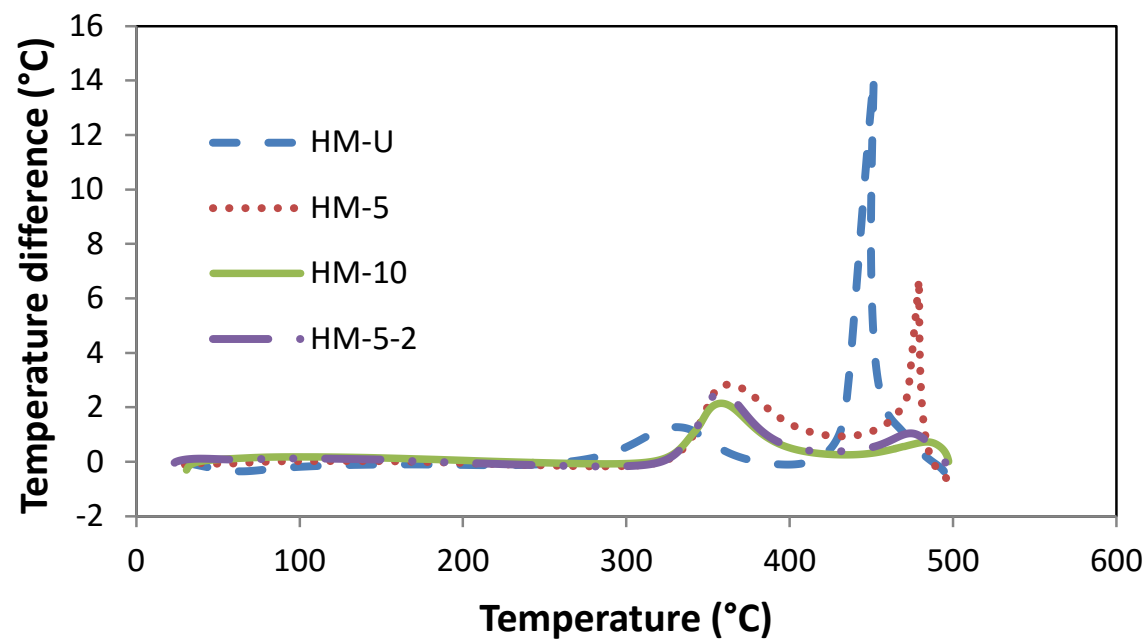

Figure 13: (b) DTA thermograms for untreated and treated hemp fibres. 
Table 1: Chemical composition of harakeke fibre

\begin{tabular}{lc}
\hline Composition & Content (\%) \\
\hline Cellulose & $60.9 \pm 4.4$ \\
\hline Hemicellulose & $27.3 \pm 4.1$ \\
\hline Lignin & $7.8 \pm 1.3$ \\
\hline Extractives & $4.0 \pm 0.3$ \\
\hline
\end{tabular}

Table 2: Abbreviations used for fibre and treatment

Fibre and Treatments

\begin{tabular}{lc}
\hline Harakeke - Untreated & HR-U \\
\hline Harakeke - Treated with 5wt\%NaOH & HR-5 \\
\hline Harakeke - Treated with $10 \mathrm{wt} \% \mathrm{NaOH}$ & HR-10 \\
\hline Harakeke - Treated with 5\%wtNaOH/2wt\% $\mathrm{Na}_{2} \mathrm{SO}_{3}$ & HR-5/2 \\
\hline Hemp - Untreated & HM-U \\
\hline Hemp - Treated with 5wt\%NaOH & HM-5 \\
\hline Hemp - Treated with $10 w t \% N a O H$ & HM-10 \\
\hline Hemp - Treated with 5wt\%NaOH/2 wt $\% \mathrm{Na}_{2} \mathrm{SO}_{3}$ & HM-5/2 \\
\hline
\end{tabular}


Table 3: Mechanical properties of untreated and alkali treated fibres. Standard deviations are included in parenthesis.

\begin{tabular}{ccccc}
\hline Fibre & $\begin{array}{c}\text { Fibre } \\
\text { Treatment }\end{array}$ & $\begin{array}{c}\text { Fibre } \\
\text { Diameter } \\
(\mathbf{m m})\end{array}$ & $\begin{array}{c}\text { Tensile } \\
\text { Strength } \\
\mathbf{( M P a )}\end{array}$ & $\begin{array}{c}\text { Young's } \\
\text { Modulus } \\
\text { (GPa) }\end{array}$ \\
\hline \multirow{2}{*}{ Harakeke } & HR-U & $13.0(1.7)$ & $804.6(305.0)$ & $20.76(8.6)$ \\
& HR-5 & $12.3(1.7)$ & $641.3(209.6)$ & $20.4(6.7)$ \\
& HR-10 & $11.4(1.5)$ & $540.3(115.5)$ & $18.7(5.6)$ \\
& HR-5/2 & $11.2(1.5)$ & $782.4(277.2)$ & $21.3(7.3)$ \\
\hline \multirow{2}{*}{ Hemp } & HM-U & $34.9(12.9)$ & $1077.6(663.2)$ & $20.9(11.8)$ \\
& HM-5 & $29.2(7.0)$ & $911.3(315.6)$ & $26.4(13.3)$ \\
& HM-10 & $29.0(9.9)$ & $790.2(350.0)$ & $26.7(14.07)$ \\
& HM-5/2 & $28.3(8.3)$ & $866.1(458.6)$ & $28.9(13.3)$ \\
\hline
\end{tabular}

Table 4: Experimental tensile strength and Weibull parameters of untreated and alkali treated fibres.

\begin{tabular}{cccc}
\hline Sample & $\begin{array}{c}\text { Tensile Strength } \\
(\mathbf{M P a})\end{array}$ & $\begin{array}{c}\text { Characteristic } \\
\text { strength, } \boldsymbol{\sigma}_{\mathbf{0}} \text { (MPa) }\end{array}$ & $\begin{array}{c}\text { Weibull Modulus, } \\
\boldsymbol{w}\end{array}$ \\
\hline HR-U & 804.6 & 923.3 & 2.4 \\
\hline HR-5 & 641.3 & 713.4 & 3.4 \\
\hline HR-10 & 540.3 & 588.8 & 4.9 \\
\hline HR-5/2 & 782.4 & 882.7 & 2.9 \\
\hline HM-U & 1077.6 & 1222.1 & 1.8 \\
\hline HM-5 & 911.3 & 1022.8 & 3.0 \\
\hline HM-10 & 790.2 & 895.3 & 2.5 \\
\hline HM-5/2 & 866.1 & 993.7 & 1.8 \\
\hline
\end{tabular}


Table 5: Crystallinity index $\left(I_{c}\right)$ of untreated and alkali treated harakeke and hemp fibres

\begin{tabular}{|c|c|c|c|}
\hline Fibre Treatments & $I_{\mathrm{am}}\left(18^{\circ} \leq 2 \theta \leq 19^{\circ}\right)$ & $I_{002}\left(22^{\circ} \leq 2 \theta \leq 23^{\circ}\right)$ & $\begin{array}{c}\text { Crystallinity Index } \\
\text { (\%) }\end{array}$ \\
\hline HR-U & 603.0 & 1912.0 & 68.5 \\
\hline HR-5 & 543.0 & 3285.0 & 83.5 \\
\hline HR-10 & 504.0 & 3691.0 & 86.3 \\
\hline HR-5/2 & 608.0 & 4061.0 & 85.0 \\
\hline HM-U & 445.0 & 1913.0 & 76.7 \\
\hline HM-5 & 438.0 & 4586.0 & 90.4 \\
\hline HM-10 & 610.0 & 6076.0 & 90.0 \\
\hline HM-5/2 & 343.0 & 3331.0 & 89.7 \\
\hline
\end{tabular}

Table 6: Summary of TGA results for untreated and treated harakeke and hemp fibres.

\begin{tabular}{cccc}
\hline Fibre Treatments & $\boldsymbol{T}_{\mathbf{1 0}} /{ }^{\circ} \mathbf{C}$ & $\boldsymbol{T}_{\mathbf{5 0}} /{ }^{\circ} \mathbf{C}$ & $\boldsymbol{T}_{\mathbf{9 0}} /{ }^{\circ} \mathbf{C}$ \\
\hline HR-U & 251 & 330 & 437 \\
HR-5 & 301 & 334 & 412 \\
HR-10 & 296 & 336 & 427 \\
HR-5/2 & 300 & 336 & 438 \\
HM-U & 214 & 335 & 450 \\
HM-5 & 317 & 351 & 472 \\
HM-10 & 309 & 346 & 460 \\
HM-5/2 & 321 & 347 & 478 \\
\hline
\end{tabular}

$T_{10} /{ }^{\circ} \mathrm{C}, T_{50} /{ }^{\circ} \mathrm{C}$ and $T_{90} /{ }^{\circ} \mathrm{C}$ means temperature at 10,50 and $90 \%$ weight loss. 